Boise State University

ScholarWorks

3-16-2015

GaSb Thermophotovoltaic Cells Grown on GaAs by Molecular Beam Epitaxy Using Interfacial Misfit Arrays

Bor-Chau Juang

University of California

Ramesh B. Laghumavarapu

University of California

Brandon J. Foggo

University of California

Paul J. Simmonds

University of California

Andrew Lin

University of California

See next page for additional authors 
Authors

Bor-Chau Juang, Ramesh B. Laghumavarapu, Brandon J. Foggo, Paul J. Simmonds, Andrew Lin, Baolai Liang, and Diana L. Huffaker 


\title{
GaSb thermophotovoltaic cells grown on GaAs by molecular beam epitaxy using interfacial misfit arrays
}

\author{
Bor-Chau Juang, ${ }^{1, \text { a) }}$ Ramesh B. Laghumavarapu, ${ }^{1}$ Brandon J. Foggo, ${ }^{1}$ Paul J. Simmonds, ${ }^{2}$ \\ Andrew Lin, ${ }^{1}$ Baolai Liang, ${ }^{2}$ and Diana L. Huffaker ${ }^{1,2}$ \\ ${ }^{1}$ Department of Electrical Engineering, University of California, Los Angeles, California 90095, USA \\ ${ }^{2}$ California NanoSystems Institute, University of California, Los Angeles, California 90095, USA
}

(Received 28 October 2014; accepted 24 February 2015; published online 16 March 2015)

\begin{abstract}
There exists a long-term need for foreign substrates on which to grow GaSb-based optoelectronic devices. We address this need by using interfacial misfit arrays to grow GaSb-based thermophotovoltaic cells directly on GaAs (001) substrates and demonstrate promising performance. We compare these cells to control devices grown on GaSb substrates to assess device properties and material quality. The room temperature dark current densities show similar characteristics for both cells on GaAs and on GaSb. Under solar simulation the cells on GaAs exhibit an open-circuit voltage of $0.121 \mathrm{~V}$ and a short-circuit current density of $15.5 \mathrm{~mA} / \mathrm{cm}^{2}$. In addition, the cells on GaAs substrates maintain $10 \%$ difference in spectral response to those of the control cells over a large range of wavelengths. While the cells on GaSb substrates in general offer better performance than the cells on GaAs substrates, the cost-savings and scalability offered by GaAs substrates could potentially outweigh the reduction in performance. By further optimizing GaSb buffer growth on GaAs substrates, Sb-based compound semiconductors grown on GaAs substrates with similar performance to devices grown directly on $\mathrm{GaSb}$ substrates could be realized. (C) 2015 AIP Publishing LLC. [http://dx.doi.org/10.1063/1.4915258]
\end{abstract}

Thermophotovoltaic (TPV) cells convert waste heat into useful electrical energy. ${ }^{1}$ The typical target thermal radiation temperature for a TPV cell is in the range of $1000-1500^{\circ} \mathrm{C}$ (corresponding to emission wavelengths of 1.6-2.3 $\mu \mathrm{m}$ ). To date, TPV cells have been realized using various III-V semiconductor materials with low bandgap energies $\left(\mathrm{E}_{\mathrm{g}}\right)$ corresponding to this emission range. These materials include InGaAs grown on InP substrates, ${ }^{2}$ and $\mathrm{GaSb}$ or $\mathrm{InGaAsSb}$ grown on GaSb substrates. ${ }^{3,4}$ However, an InGaAs TPV cell lattice-matched to an InP substrate has a bandgap of $0.74 \mathrm{eV}$ at room temperature, which sacrifices photon conversion for longer wavelengths. In contrast, InGaAsSb materials latticematched to GaSb substrates cover the entire wavelength range of interest. The high carrier mobility and the flexibility of bandgap engineering are the major advantages of choosing Sb-based materials.

However, the high cost and small size $(\leq 4$ in.) of commercially available GaSb substrates is a huge obstacle to large volume TPV cell production. In addition, semiinsulating GaSb substrates are not currently available, which could exclude certain device architectures. As a result, there is great interest in transferring GaSb-based devices onto foreign substrates such as GaAs or silicon. ${ }^{5,6}$ Some attempts have been made to develop GaSb material on GaAs substrates using metamorphic growth which needs a long deposition time. ${ }^{7}$ Wafer bonding has also been used to integrate $\mathrm{GaSb}$ with GaAs or silicon substrates, ${ }^{8-10}$ but it requires significant processing time before and after device growth.

We propose a different approach that uses interfacial misfit (IMF) array technology to grow GaSb-based devices

\footnotetext{
${ }^{\text {a) }}$ Author to whom correspondence should be addressed. Electronic mail: bcjuang@ucla.edu
}

on GaAs substrates and could be more attractive for high volume, high-throughput manufacture. A well-confined IMF array consists of a uniformly spaced network of $90^{\circ}$ misfit Lomer dislocations that almost fully relieve the 7.8\% latticemismatched strain generated at the GaSb-GaAs interface, allowing the heteroepitaxy to take place with a very low dislocation density. ${ }^{11,12} \mathrm{GaSb}$ with very high crystallographic quality and more than $99 \%$ strain relaxation can be grown via IMF arrays on GaAs substrates without the need for thick metamorphic buffer growth, or lengthy post-growth processing. ${ }^{13}$ Previously, InGaAsSb photodetectors grown on IMF arrays have been demonstrated to possess high responsivities and show comparable performance to identical detectors grown directly on GaSb substrates. ${ }^{14,15}$

In this letter, we explore the feasibility of developing high quality GaSb TPV cells on commercially viable, lowcost, large format GaAs substrates using the IMF-based approach. Two GaSb TPV cells were grown by a Veeco Gen 930 solid-source molecular beam epitaxy (MBE) system, one on an unintentionally doped $\mathrm{GaSb}(001)$ substrate and the other on a semi-insulating GaAs (001) substrate using the IMF-based approach. The cell structure was designed to optimize photon conversion efficiency using Sentaurus software. The emitter and base doping concentrations and thicknesses were adjusted and optimized via an iterative process. The TPV device structure (from bottom to top) consists of a $500 \mathrm{~nm} n^{+}-\mathrm{GaSb}$ contact layer, a $50 \mathrm{~nm} n$-AlGaSb backbarrier layer, a $2 \mu \mathrm{m} n$-GaSb base layer, a $450 \mathrm{~nm} p$-GaSb emitter layer, a $50 \mathrm{~nm} p-\mathrm{AlGaSb}$ window layer, and a $50 \mathrm{~nm}$ $p^{+}$-GaSb contact layer (Figure 1(a)). Te and Be were used as the n-type and p-type dopants for GaSb, respectively. TPV cells grown on a GaAs substrate have exactly the same structure except for the underlying IMF array (Figure 1(b)). 
(a)

\begin{tabular}{|c|}
\hline $50 \mathrm{~nm} \quad \mathrm{p}$-GaSb \\
\hline $50 \mathrm{~nm}$-AlGaSb \\
\hline $450 \mathrm{~nm} \quad \mathrm{p}$-GaSb \\
\hline $2000 \mathrm{~nm}$ n-GaSb \\
\hline $50 \mathrm{~nm}$ n-AlGaSb \\
\hline $500 \mathrm{~nm} \quad \mathrm{n}$-GaSb \\
\hline GaSb buffer \\
\hline un-GaSb substrate \\
\hline
\end{tabular}

(b)

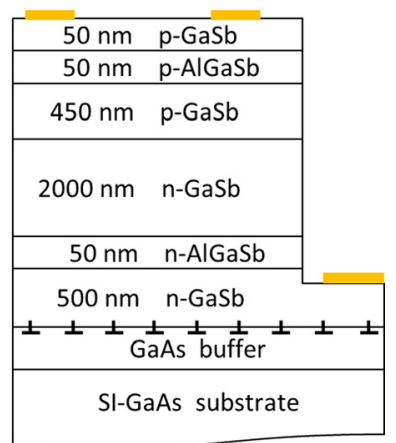

FIG. 1. Device structures of (a) TPV cells grown directly on GaSb substrate and (b) TPV cells based on IMF arrays grown on GaAs substrate.

Details of the IMF growth can be found elsewhere. ${ }^{11}$ When the growths were completed, the samples were cooled down under a reduced antimony overpressure to avoid excessive accumulation of antimony on the surface. ${ }^{16}$ Anti-reflection layers or passivation layers were not used in this study. The authors are aware that surface recombination will be an issue for shorter wavelength photons $(<800 \mathrm{~nm})$ mainly absorbed close to the front surface. Since this is a comparative study between devices grown with and without IMF array ( $\mathrm{GaSb}$ TPV cells grown on GaAs and GaSb substrates), any effects resulting from the fact that passivation layers were not used are common to both samples.

Regardless of substrate type, circular mesas were fabricated with $100 \mu \mathrm{m}, 200 \mu \mathrm{m}, 400 \mu \mathrm{m}$, and $800 \mu \mathrm{m}$ diameters using standard photolithographic and mesa etching techniques. ${ }^{14,17}$ An inductively coupled plasma etcher $\left(\mathrm{BCl}_{3} / \mathrm{Ar}\right)$ was used to dry-etch the mesas down to the $n^{+}$-GaSb layer to create electrically isolated devices and form the bottom contact. $n$ - and $p$-GaSb ohmic contacts were deposited using $\mathrm{Ni}$ $(10 \mathrm{~nm}) / \mathrm{Ge}(50 \mathrm{~nm}) / \mathrm{Au}(200 \mathrm{~nm})$ and $\mathrm{Ti}(50 \mathrm{~nm}) / \mathrm{Pt}(50 \mathrm{~nm}) /$ $\mathrm{Au}(100 \mathrm{~nm})$, respectively, using e-beam evaporation. Contact resistances were measured using a standard transmission line method (TLM). The $p$-GaSb Ti/Pt/Au contact exhibits an ohmic contact with resistivity of $\sim 6.5 \times 10^{-6} \Omega \cdot \mathrm{cm}^{2}$ without further thermal annealing. The $n-\mathrm{GaSb} \mathrm{Ni} / \mathrm{Ge} / \mathrm{Au}$ metal contact required rapid thermal annealing (in a nitrogen environment) for $30 \mathrm{~s}$ at $300^{\circ} \mathrm{C}$ to obtain ohmic behavior with resistivity of $\sim 2 \times 10^{-4} \Omega \cdot \mathrm{cm}^{2}$. It is well known that $n$-GaSb is difficult to form ohmic contacts with due to the doping limit for $\mathrm{Te}^{18,19}$ and the Fermi-level pinning in the valence band at the surface. ${ }^{20}$ We therefore consider this contact resistance to be reasonable. After device fabrication, the samples were soaked in $\mathrm{HCl}: \mathrm{H}_{2} \mathrm{O}: \mathrm{H}_{2} \mathrm{O}_{2}(100: 100: 1)$ to eliminate surface defects at mesa sidewalls created during the dry-etch process.

The inverse of the zero bias dynamic resistance-area product $\left(1 / \mathrm{R}_{0} \mathrm{~A}\right)$ as a function of perimeter to area ratio $(\mathrm{P} /$ A) of all cells is measured by an Agilent $4156 \mathrm{C}$ parameter analyzer. $1 / \mathrm{R}_{0} \mathrm{~A}$ values measured after wet etching indicate the surface leakage at the mesa sidewalls has been significantly reduced compared to those without wet etching for both samples (Figure 2). Even though the $1 / \mathrm{R}_{0} \mathrm{~A}$ of the control cell is still somewhat limited by the mesa sidewalls after wet etching, in the IMF-based cell it is nearly independent of mesa size, suggesting that leakage currents are still bulklimited.

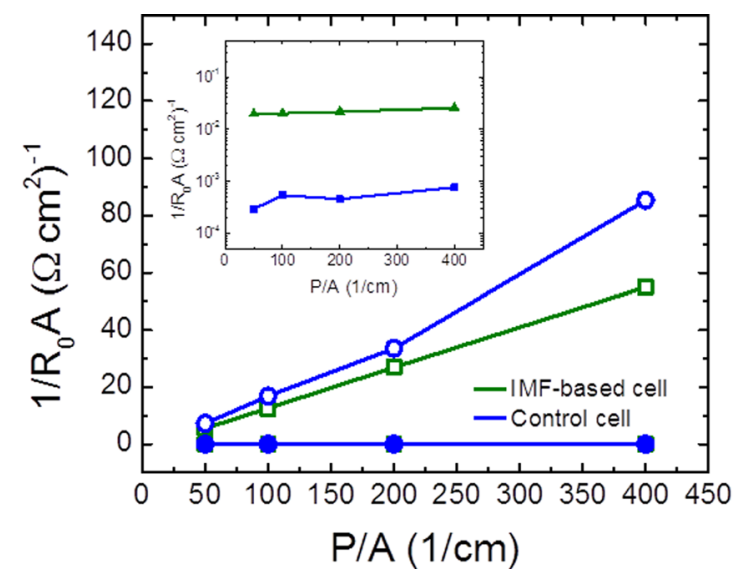

FIG. 2. The $1 / \mathrm{R}_{0} \mathrm{~A}$ product as a function of $\mathrm{P} / \mathrm{A}$ for the IMF-based cells and control cells. The open symbols are the $1 / \mathrm{R}_{0} \mathrm{~A}$ of both cells without any treatment, and the solid symbols are those after soaking in $\mathrm{HCl}$ etchant ( $\mathrm{HCl}: \mathrm{H}_{2} \mathrm{O}: \mathrm{H}_{2} \mathrm{O}_{2}=100: 100: 1$ ). The inset is the $1 / \mathrm{R}_{0} \mathrm{~A}$ against $\mathrm{P} / \mathrm{A}$ plotted in semi-logarithmic scale for both cells after wet etching. Lines connecting the data points are used as a guide to the eye.

Cross-sectional transmission electron microscopy (TEM) and atomic force microscopy (AFM) are used to investigate the $\mathrm{GaSb} / \mathrm{GaAs}$ interface and topology of TPV cells. Crosssectional TEM, taken with FEI Titan S/TEM, suggests an abrupt, well-formed periodic IMF array (Figure 3). Every black dot indicates a $90^{\circ}$ misfit dislocation separated from its neighbor by $5.6 \mathrm{~nm}$ due to the difference in size of the unit cells of GaSb and GaAs. ${ }^{12}$ Using AFM, monolayer-high terraces are found to cover most of the surface of the control cell, as shown in Figure 4(a). However, instead of the concentric pyramidal mounds that are typically reported for the homoepitaxial GaSb surface, ${ }^{21}$ spiral pyramidal mounds are also observed with a very low density $\left(<10^{5} \mathrm{~cm}^{-2}\right)$. Similar spiral pyramidal mounds can also be found on the IMF-based cell, albeit with higher density (Figure 4(b)). The origin of the spiral pyramidal mounds is widely considered to be threading dislocations generated from the coalescence of islands during the initial stages of $\mathrm{GaSb}$ growth. ${ }^{22,23} \mathrm{GaSb}$ homoepitaxy is believed to start with island formation, and these islands eventually merge to create a uniform layer. The ideal IMFbased GaSb follows the same growth mode with a uniform distribution of $90^{\circ}$ misfits in [110] or [1-10] direction. While

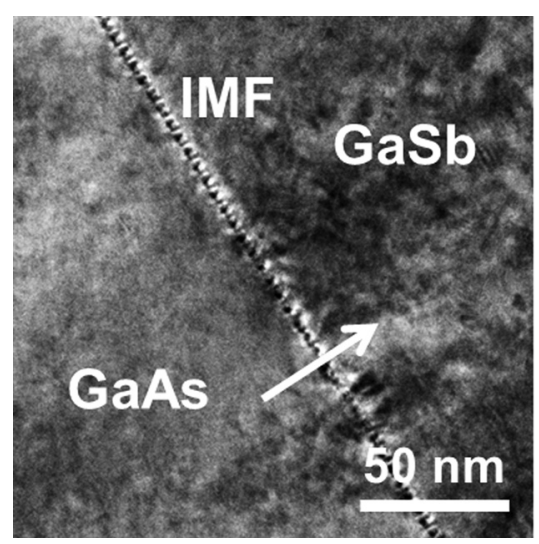

FIG. 3. Cross-sectional TEM along [110] of a GaSb buffer grown on GaAs. The dark spots at the interface indicate the periodic locations of the misfit dislocations. 

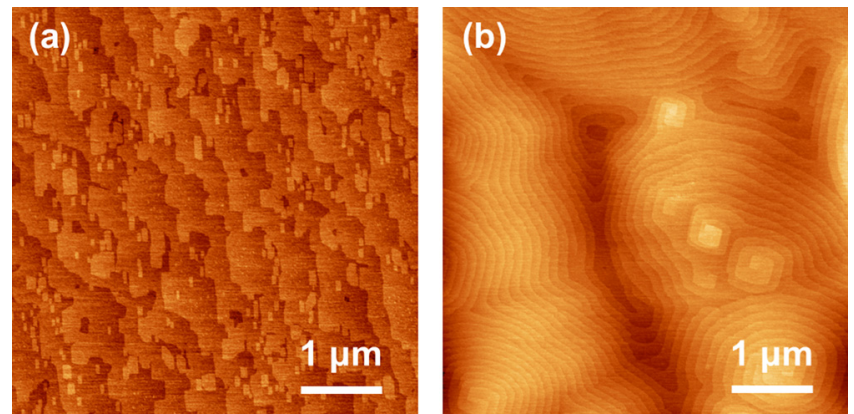

FIG. 4. AFM images ( $5 \mu \mathrm{m} \times 5 \mu \mathrm{m})$ of (a) a TPV control cell grown on a GaSb substrate and (b) an IMF-based TPV cell grown on a GaAs substrate. The roughness (r.m.s.) values of (a) and (b) are $0.16 \mathrm{~nm}$ and $0.51 \mathrm{~nm}$, respectively.

the $90^{\circ}$ misfits is the predominant strain relief mechanism of the IMF array, a minority of $60^{\circ}$ misfits may still randomly nucleate and cause threading dislocations in the GaSb. The higher density of spiral pyramidal mounds $\left(\sim 2 \times 10^{7} \mathrm{~cm}^{-2}\right)$ in the IMF-based cell may indicate a higher density of threading dislocations.

Generally, although smaller sized mesas tend to exhibit a relatively strong effect from the sidewall surface, they also exhibit better diode characteristics (e.g., ideality factor) since they have less bulk-related defects. ${ }^{24,25}$ However, the top exposed surface areas of the small size mesas $(100 \mu \mathrm{m}$ and $200 \mu \mathrm{m})$ are normally difficult to underfill with the coupled light spot from the fiber while maintaining a reliable optical measurement. Therefore, $200 \mu \mathrm{m}$ mesas are used to study the dark I-V characteristics, and $400 \mu \mathrm{m}$ mesas are used for optical measurements. TPV cells with each size of cell mesa are chosen and measured from at least 5 different locations on each sample. Extra care is taken prior to all optical measurements by checking the dark I-V characteristics of each diode, and the data reported here are from the best-performing (but still representative) cells of both samples. From dark I-V characterization, the ideality factors are derived from the slopes at forward bias, which are 1.6 for the IMF-based cells and 1.3 for the control cells. The relatively larger ideality factor of the IMF-based cell indicates greater contribution from generation-recombination current. Average dark current densities in the IMF-based cell and the control cell at $-10 \mathrm{mV}$ are measured to be $264 \pm 9.39 \mu \mathrm{A} / \mathrm{cm}^{2}$ and $5.08 \pm 0.54 \mu \mathrm{A} / \mathrm{cm}^{2}$, respectively, indicating the magnitude of dark leakage current of the cells on GaAs is about 50 times larger than that on $\mathrm{GaSb}$ at room temperature (Figure 5(a)). The optical response of TPV cells was measured under an Oriel 1 sun, AM 1.5 solar simulator using a Keithley 2400 source meter. The $400 \mu$ m-diameter control cell exhibits an open-circuit voltage $\left(\mathrm{V}_{\mathrm{OC}}\right)$ of $0.301 \mathrm{~V}$, a short-circuit current density $\left(\mathrm{J}_{\mathrm{SC}}\right)$ of $16.1 \mathrm{~mA} / \mathrm{cm}^{2}$, and a fill factor $(\mathrm{FF})$ of $62 \%$. In comparison, the same size IMF-based cell shows a $\mathrm{V}_{\mathrm{OC}}$ of $0.121 \mathrm{~V}$, a $\mathrm{J}_{\mathrm{SC}}$ of $15.5 \mathrm{~mA} / \mathrm{cm}^{2}$, and a $\mathrm{FF}$ of $40 \%$ (Figure 5 (b)). The shunt resistance in a $400 \mu \mathrm{m}$-diameter IMF-based cell is $29.1 \mathrm{k} \Omega$, while it is $1.47 \mathrm{M} \Omega$ in a control cell. The difference in the shunt resistances may be attributed to the increased density of threading dislocations in the IMF-based cells that is implied by the higher mound density we saw in by AFM (Figure 4(b)). Since we have no reliable way to
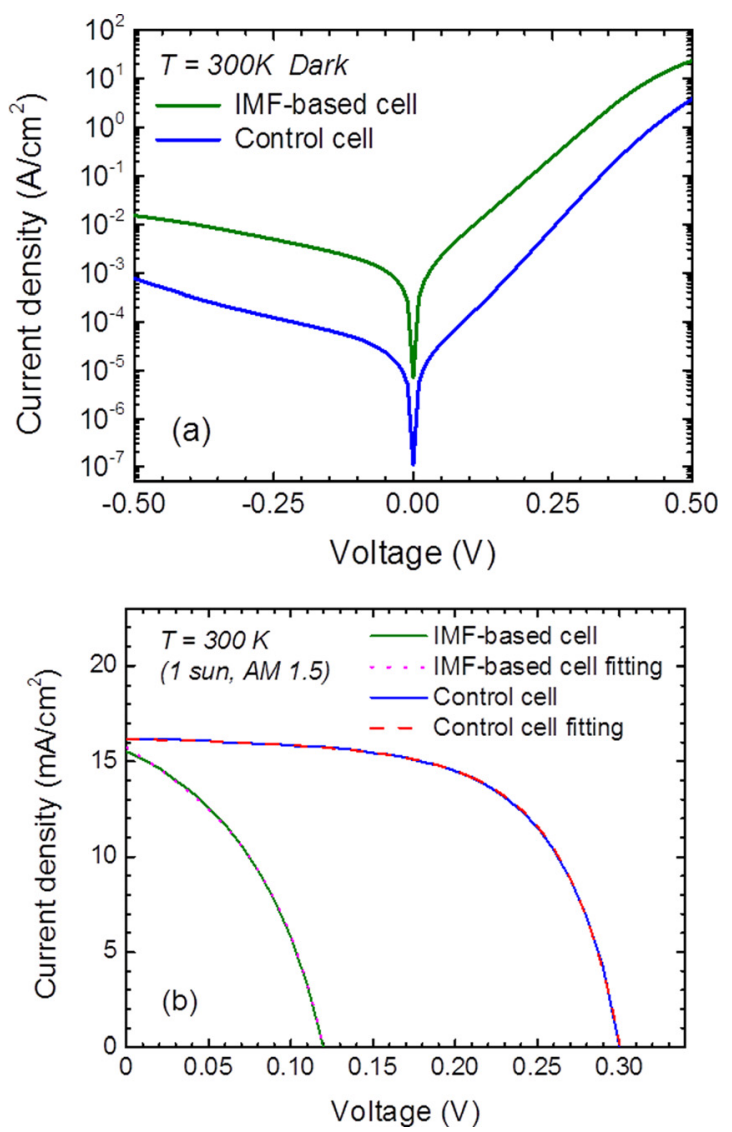

FIG. 5. Dark current density as a function of applied voltage of the $200 \mu \mathrm{m}-$ diameter TPV cells on GaAs and GaSb substrates. (b) Current densityvoltage curves (solid lines) of the $400 \mu$ m-diameter TPV cells under 1 sun and AM 1.5 condition. The dashed lines are the fitting via the double diode model for both cells.

calculate the actual mound density in the control cell (estimated $<10^{5} \mathrm{~cm}^{-2}$ ), it is difficult to establish a clear relationship between this number and the lower performance of the IMF-based cell. However, we expect that the IMF cell performance would increase with a decrease in the number of mounds. The higher density of threading dislocations in the IMF cell also leads to the reduced $\mathrm{V}_{\mathrm{OC}}$ in Figure 5(b), and which was also observed by DeMeo et al. ${ }^{26}$

Fitting with a double diode model was performed to understand the inferior IMF-based cell performance

$$
\begin{aligned}
\mathrm{J}= & \mathrm{J}_{\mathrm{L}}-\mathrm{J}_{01} \exp \left(\frac{\mathrm{q}\left(\mathrm{V}+\mathrm{JR}_{\mathrm{s}}\right)}{\mathrm{k}_{\mathrm{B}} \mathrm{T}}-1\right) \\
& -\mathrm{J}_{02} \exp \left(\frac{\mathrm{q}\left(\mathrm{V}+\mathrm{JR}_{\mathrm{s}}\right)}{2 \mathrm{k}_{\mathrm{B}} \mathrm{T}}-1\right)-\frac{\mathrm{V}+\mathrm{JR}_{\mathrm{s}}}{\mathrm{R}_{\mathrm{sh}}},
\end{aligned}
$$

where $\mathrm{k}_{\mathrm{B}}$ is the Boltzmann constant, $\mathrm{T}$ is the ambient temperature, $R_{S}$ is the series resistance, $R_{s h}$ is the shunt resistance, $\mathrm{J}_{\mathrm{L}}$ is the cell-generated photocurrent density, and $\mathrm{J}_{01}$ and $\mathrm{J}_{02}$ are the saturation current densities for the first and the second diodes, respectively.

Fitting the experimental data to the double diode model gave us the parameter values shown in Table $I_{.} R_{s}$ and $R_{s h}$ values were calculated directly from the measured slope of current density-voltage characteristics near the open-circuit and short-circuit conditions, respectively. $\mathrm{J}_{01}$ represents the saturation current dominated by the carrier recombination at 
TABLE I. The double diode model fitted parameters from the experimental data of the IMF-based cell and the control cell measured under 1 sun and AM 1.5 condition by an solar simulator.

\begin{tabular}{|c|c|c|c|c|c|}
\hline Device description & $\mathrm{J}_{\mathrm{L}}\left(\mathrm{A} / \mathrm{cm}^{2}\right)$ & $\mathrm{J}_{01}\left(\mathrm{~A} / \mathrm{cm}^{2}\right)$ & $\mathrm{J}_{02}\left(\mathrm{~A} / \mathrm{cm}^{2}\right)$ & $\mathrm{R}_{\mathrm{s}}\left(\Omega \cdot \mathrm{cm}^{2}\right)$ & $\mathrm{R}_{\mathrm{sh}}\left(\Omega \cdot \mathrm{cm}^{2}\right)$ \\
\hline Control cell & 16.19 & $1.41 \times 10^{-7}$ & $6.47 \times 10^{-5}$ & 4.3 & 550.0 \\
\hline IMF-based cell & 16.18 & $1.66 \times 10^{-4}$ & $1.06 \times 10^{-3}$ & 4.5 & 22.7 \\
\hline
\end{tabular}

the surface and the bulk region at high voltage. $\mathrm{J}_{02}$ suggests carrier recombination in the junction where the ideality factor approaches two at lower voltage. Nearly three orders of magnitude difference in $\mathrm{J}_{01}$ between the IMF-based cell and the control cell is significant at high voltage, and indicates the drop in $\mathrm{V}_{\mathrm{OC}}$ is strongly affected by recombination in the bulk. This effect could be explained by the higher density of dislocations in the IMF-based cell, leading to an enhanced Shockley-Read-Hall (SRH) recombination process in the bulk. Model fitting shows that the difference in $\mathrm{R}_{\mathrm{sh}}$ is not a limiting factor in the reduction in $\mathrm{V}_{\mathrm{OC}}$, which suggests shunt paths through the mesa sidewall do not play a major role in this case.

We measured the spectral response of the TPV cells to evaluate the external quantum efficiency (EQE) using a SuperK EXTREME supercontinuum laser and a SRS lock-in amplifier. The laser power density at different wavelengths was determined and calibrated prior to the measurement. The measured data is smoothed via the adjacent-averaging method to remove background noise. For wavelengths below $0.8 \mu \mathrm{m}$, in both cells most of the incident photons are either lost from reflection at the front surface or by carrier recombination before they reach the junction. From wavelengths of $0.8 \mu \mathrm{m}$ up to $1.5 \mu \mathrm{m}$, the EQE values of the IMF-based cell remain above $30 \%$, and then start to decrease at longer wavelength, followed by the cutoff at the GaSb band edge (Figure 6). The lower EQE values near the bandgap of the cells may be due to insufficient base thickness that reduces the collection efficiency. The IMF-based cell in particular, shows greater reduction in EQE near the bandgap, suggesting an additional loss of long wavelength photons. The faster drop in EQE of the IMF-based cell compared to the control cell is due to the difference in absorption rates of photons and increased number of non-radiative recombination centers

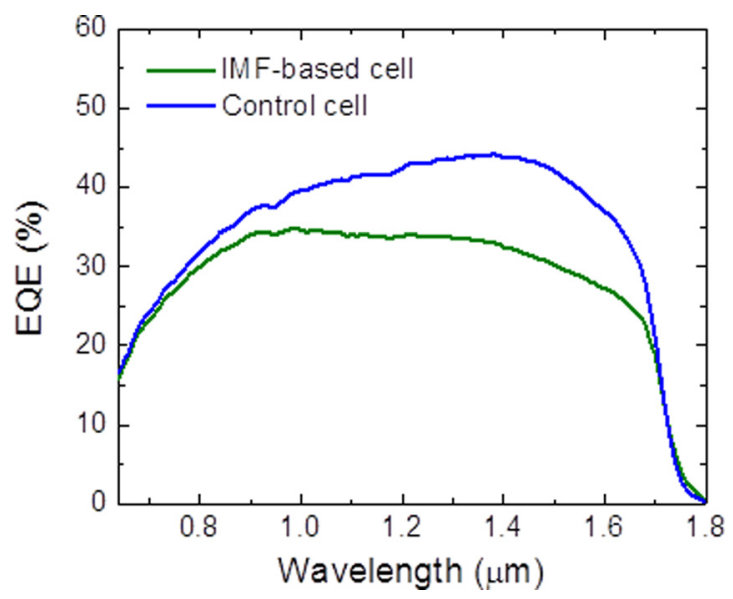

FIG. 6. External quantum efficiency curves of the $400 \mu \mathrm{m}$ diameter TPV cells. near the GaSb-GaAs interface. Even though the majority of IMF arrays are $90^{\circ}$ misfit dislocations confined at the interface, the randomly formed $60^{\circ}$ misfit dislocations representing imperfect relaxation affect the epitaxial layers above. The longer wavelength photons will travel deeper into the devices and be absorbed near the GaSb/GaAs interface. For example, the absorption depth calculation based on refractive indices of $\mathrm{GaSb}$ at different wavelengths shows that above $95 \%$ of $0.8 \mu \mathrm{m}$ photons transmitted into device will be absorbed in the first $1 \mu \mathrm{m}$, while only about $50 \%$ of $1.55 \mu \mathrm{m}$ photons will be absorbed within the same thickness. After traveling $2.6 \mu \mathrm{m}$ down into the device (reaching the bottom contact), there are still about $20 \%$ of $1.55 \mu \mathrm{m}$ photons that have not been absorbed. As a result of the increasing number of non-radiative recombination centers near the GaSb/GaAs interface, those remaining long wavelength photons are more likely to be lost due to the shorter SRH lifetime. As a result they will not reach the contacts, unlike those in the control cell. However, it is encouraging that the difference in EQE spectra between the control and IMF-based cells is within $\sim 10 \%$ over the entire range of wavelengths studied. Further optimization of IMF growth and studies to reduce carrier recombination near the GaSb-GaAs interface are still needed to improve cell performance.

In conclusion, we have demonstrated that GaSb-based TPV cells delivering promising performance can be grown on cost-effective GaAs substrates using IMF arrays. The dark current density of the IMF-based cell at $-10 \mathrm{mV}$ is approximately 50 times higher than that of the control cell at room temperature. Despite this, the IMF-based cell maintains comparable photocurrent density $\left(\sim 16 \mathrm{~mA} / \mathrm{cm}^{2}\right)$ to that of the control cell under 1 sun and AM 1.5 condition. The reduced $\mathrm{V}_{\mathrm{OC}}$ of the IMF-based cell is analyzed via a double diode model and shown to be limited by a higher density of non-radiative recombination centers in the bulk region caused by an elevated number of threading dislocations. Spectral response measurements show that the EQE spectra of the IMF-based cell and the control cell retain similar features and are within $10 \%$ of one another over a large range of wavelengths. This work represents an encouraging step towards obtaining cost-effective TPV cells. We believe that the quality of IMF-based GaSb devices can be further improved by optimizing the IMF growth mode to reduce the influence of the randomly formed $60^{\circ}$ threading dislocations. We therefore expect III-Sb TPV cells grown on GaAs will continue to improve until their performance competes directly with cells grown on $\mathrm{GaSb}$, but at significantly reduced cost.

The authors acknowledge the financial support from the California Energy Commission's Public Interest Energy Research (PIER) Program to conduct this work. 
${ }^{1}$ T. J. Coutts, Renewable Sustainable Energy Rev. 3, 77 (1999).

${ }^{2}$ R. S. Tuley, J. M. S. Orr, R. J. Nicholas, D. C. Rogers, P. J. Cannard, and S. Dosanjh, Semicond. Sci. Technol. 28, 015013 (2013).

${ }^{3}$ M. G. Mauk and V. M. Andreev, Semicond. Sci. Technol. 18, S191 (2003).

${ }^{4}$ M. W. Dashiell, J. E. Beausang, H. Ehsani, G. J. Nichols, D. M. Depoy, L. R. Danielson, P. Talamo, K. D. Rahner, E. J. Brown, S. R. Burger, P. M. Fourspring, W. E. Topper, P. F. Baldasaro, C. A. Wang, R. K. Huang, M. K. Connors, G. W. Turner, Z. A. Shellenbarger, G. Taylor, J. Z. Li, R. Martinelli, D. Donetski, S. Anikeev, G. L. Belenky, and S. Luryi, IEEE Trans. Electron Devices 53, 2879 (2006).

${ }^{5}$ Q. Fan, A. L. C. Lim, G. J. Conibeer, C. W. Bumby, P. A. Shields, R. J. Nicholas, and S. K. Haywood, Photovoltaic Specialists Conference (2002), p. 951.

${ }^{6}$ L. Zheng, S. K. Haywood, N. J. Mason, and G. Verschoor, IEE Proc.: Optoelectron. 147, 205 (2000).

${ }^{7}$ J. M. Fastenau, D. Lubyshev, Y. Qiu, A. W. K. Liu, E. J. Koerperick, J. T. Olesberg, and D. Norton, J. Vac. Sci. Technol., B 31, 03 C106 (2013).

${ }^{8}$ Y. Zheng, P. D. Moran, Z. F. Guan, S. S. Lau, D. M. Hansen, T. F. Kuech, T. E. Haynes, T. Hoechbauer, and M. Nastasi, J. Electron Mater. 29, 916 (2000).

${ }^{9}$ C. A. Wang, D. A. Shiau, P. G. Murphy, P. W. O'Brien, R. K. Huang, M. K. Connors, A. C. Anderson, D. Donetsky, S. Anikeev, G. Belenky, D. M. Depoy, and G. Nichols, J. Electron Mater. 33, 213 (2004).

${ }^{10}$ M. Grzesik, S. R. Vangala, and W. D. Goodhue, J. Electron Mater. 42, 679 (2013).

${ }^{11}$ S. H. Huang, G. Balakrishnan, A. Khoshakhlagh, A. Jallipalli, L. R. Dawson, and D. L. Huffaker, Appl. Phys. Lett. 88, 131911 (2006).

${ }^{12}$ A. Jallipalli, G. Balakrishnan, S. H. Huang, A. Khoshakhlagh, L. R. Dawson, and D. L. Huffaker, J. Cryst. Growth 303, 449 (2007).
${ }^{13}$ C. J. Reyner, J. Wang, K. Nunna, A. Lin, B. Liang, M. S. Goorsky, and D. L. Huffaker, Appl. Phys. Lett. 99, 231906 (2011).

${ }^{14}$ K. C. Nunna, S. L. Tan, C. J. Reyner, A. R. J. Marshall, B. Liang, A. Jallipalli, J. P. R. David, and D. L. Huffaker, IEEE Photonics Technol. Lett. 24, 218 (2012).

${ }^{15}$ E. Plis, J. B. Rodriguez, G. Balakrishnan, Y. D. Sharma, H. S. Kim, T. Rotter, and S. Krishna, Semicond. Sci. Technol. 25, 085010 (2010).

${ }^{16}$ E. J. Koerperick, L. M. Murray, D. T. Norton, T. F. Boggess, and J. P. Prineas, J. Cryst. Growth 312, 185 (2010).

${ }^{17}$ A. Jallipalli, K. Nunna, M. N. Kutty, G. Balakrishnan, G. B. Lush, L. R. Dawson, and D. L. Huffaker, Appl. Phys. Lett. 95, 072109 (2009).

${ }^{18}$ C. A. Wang, D. A. Shiau, R. K. Huang, C. T. Harris, and M. K. Connors, J. Cryst. Growth 261, 379 (2004).

${ }^{19}$ F. Nakamura, K. Taira, K. Funato, and H. Kawai, J. Cryst. Growth 115, 474 (1991).

${ }^{20}$ P. S. Dutta, H. L. Bhat, and V. Kumar, J. Appl. Phys. 81, 5821 (1997).

${ }^{21}$ B. Z. Nosho, B. R. Bennett, E. H. Aifer, and M. Goldenberg, J. Cryst. Growth 236, 155 (2002).

${ }^{22}$ B. Brar, D. Leonard, and J. H. English, in Compound Semiconductors 1994, edited by H. Goronkin and U. Mishra (IOP Publishing Ltd., Bristol, 1995).

${ }^{23}$ P. M. Thibado, B. R. Bennett, M. E. Twigg, B. V. Shanabrook, and L. J. Whitman, J. Vac. Sci. Technol., A 14, 885 (1996).

${ }^{24}$ S. Chih-Tang, R. N. Noyce, and W. Shockley, Proc. IRE 45, 1228 (1957).

${ }^{25}$ S. M. Sze and K. K. Ng, Physics of Semiconductor Devices (Wiley, New York, 1981).

${ }^{26}$ D. DeMeo, C. Shemelya, C. Downs, A. Licht, E. Magden, T. Rotter, C. Dhital, S. Wilson, G. Balakrishnan, and T. Vandervelde, J. Electron Mater. 43, 902 (2014). 